\title{
Human Resource Planning Process and Its Influence to the Performance of Health Sector in Uganda: A Case Study of International Hospital Kampala (IHK)
}

\author{
Bakaki Ivan 1,2, Dickson Turyareeba $^{3,4}$, Christopher Wagima ${ }^{1,2}$, Richard Wemesa ${ }^{2,5,6}$, \\ Eldard Mukasa Ssebbaale ${ }^{7,8}$, Kizito Moses ${ }^{9,10}$ \\ ${ }^{1}$ Faculty of Business and Management, International University of East Africa, Kampala, Uganda \\ ${ }^{2}$ King Ceasor University, Kampala, Uganda \\ ${ }^{3}$ Department of Economics, Makerere University, Kampala, Uganda \\ ${ }^{4}$ Business School, King Ceasor University, Kampala, Uganda \\ ${ }^{5}$ Uganda Institute of Banking \& Financial Services, Kampala, Uganda \\ ${ }^{6}$ Unicaf University, Lusaka Zambia and Lilongwe Malawi \\ ${ }^{7}$ Cavendish University, Kampala, Uganda \\ ${ }^{8}$ Department of Business, King Ceasor University, Kampala, Uganda \\ ${ }^{9}$ Department of ICT/Math, International University of East Africa, Kampala, Uganda \\ ${ }^{10}$ Victoria University, Kampala, Uganda \\ Email: bakakiivan2012@gmail.com,dturyareba@mubs.ac.ug, chriswagima@gmail.com, Richie.wemesa@gmail.com, \\ ssebbaalemukasa@gmail.com, kztmoz@gmail.com
}

How to cite this paper: Ivan, B., Turyareeba, D., Wagima, C., Wemesa, R., Ssebbaale, E. M., \& Moses, K. (2020). Human Resource Planning Process and Its Influence to the Performance of Health Sector in Uganda: A Case Study of International Hospital Kampala (IHK). Open Journal of Business and Management, 8, 2248-2261.

https://doi.org/10.4236/ojbm.2020.85137

Received: July 22, 2020

Accepted: September 14, 2020

Published: September 17, 2020

Copyright $\odot 2020$ by author(s) and Scientific Research Publishing Inc. This work is licensed under the Creative Commons Attribution International License (CC BY 4.0). http://creativecommons.org/licenses/by/4.0/ (c) (i) Open Access

\begin{abstract}
The purpose of this paper is to investigate the process of human resource planning and its influence to the performance of the health sector in Uganda, considering a case study of IHK. The study adopts a descriptive research design. Data was collected using self-administered questionnaires. The study finds that External Scanning and Determination of Goals are the most important components of human resource planning process that influence performance at IHK. The results nevertheless show that the other components of human resource planning process such as Internal Scanning, Performance Gap Analysis, Decide Human Resource Priorities, Environmental Scanning and as well as Measuring, Monitoring and Reporting the Progress are correspondingly important components of human resource planning process that influence performance at IHK. Therefore, the study recommends that ministry of health should work towards matching human resource planning process with organizational strategic goals, and to achieve this, the ministry should clearly define its vision and mission to the staff and partner organizations in a concise manner,
\end{abstract}


which will help them focus and deliver good results and thus enhance performance of the entire health sector in Uganda. The study further suggests that Human Resource Planning Departments IHK should focus mostly on scanning the External Community and Determination of Goals components of Human Planning Resource Process and IHK should embrace the use of modern technology in the recruitment and selection of staff.

\section{Keywords}

Human Resource Planning Process, Organizational Performance, Health Sector, Uganda

\section{Introduction}

Every organization requires diverse resources for its growth and development. Among these resources are human resource, financial resources and technical resources (Keep, 1989). Of these three, human resource plays the most important role. According to (Rao, 2010) human resource planning contributes significantly to the strategic management process by providing the means to accomplish the outcomes desired from the planning process. In essence, the human demands and needs are derived from strategic and operating planning and then compared with human resource availability.

Governments in Africa seem to agree that human resource planning is among the critical issues which need serious attention, in their public service management and employee policy. This is because of low productivity, lack of proper human resource planning, erosion of work ethics, indiscipline, blatant violation of rules, regulations and procedures, weak control and corruption have been observed as a common feature in the service Inspectorate of Government noted. More specifically, the Uganda government presents a very critical picture of its own public service: staff is poorly managed, has a low integrity, and uses limited resources inefficiently. "A disabling public service culture" is also lamented.

Planning the allocation of sufficient financial resources in the health sector enhances its efficiency and improves the overall performance of the sector. For the case of Uganda, according to (Annual Health Sector Performance Report, FY 2013/14), there has been just a slight improvement in the level of investments into the health sector over the HSSIP. The percentage of approved posts filled by health workers (public facilities) increased just slightly from 56\% in 2010/11 to $63 \%$ in 2012-13, up to $69 \%$ in 2013/14, due to recruitment exercise by $\mathrm{MoH}$ and enhanced recruitment by partners. Remote districts however, have not fully benefited from the recruitment drive owing to personnel tendency to avoid areas with poor social infrastructure. In some districts like Pader in northern Uganda having, only $35 \%$ of its posts filled ( $\mathrm{MoH}$ Report, 2008a). Shortage of critical staff especially midwives doctors, nutritionist, anesthetists, pharmacy assistants 
and laboratory staff has greatly compromised the quality of health service hence poor performance of health sector. Attrition in PNFP organizations is high as health workers have in the past few years joined the public sector following Government's decision to increase salaries and incentives for civil servants (MoH Report, 2008b). Migration of health workers is occurring at alarming rate due to more attractive salaries and opportunities abroad. An incentives scheme for human resource in hard-to-reach areas was initiated but sustainability remained a challenge. Given the numerous weaknesses in leadership and management of human resources planning at all levels of the health system in Uganda, as well as poor and slow recruitment practices and poor distribution of health workers, this study considers a case of International Hospital Kampala (IHK) to assess the role of human resource planning on the performance of the health sector.

\subsection{Purpose of the Study}

The purpose of the study is to investigate the process of human resource planning and its influence to the performance of health sector in Uganda, considering a case study of IHK.

\subsection{Geographical and Time Scope of the Study}

The study was conducted at International Hospital Kampala located in Makindye Division south East of Kampala, about six kilometers (3.7 miles) from the central business district of kampala; Plot 4686 St Barnabas Road, Kisugu-Namuwongo. The study focused on the period ranging from 2016 to 2017.

\section{Theoretical Framework}

This study is guided by three theories of Human Resource Planning and Organizational Performance, namely the Ouchi's Theory Z, Arm Strong (2008) theory and Hendry (1995) theory.

\subsection{Ouchi's Theory Z}

This theory is rooted in the idea that employees who are involved in and committed to an organization will be motivated to increase productivity. Based on the Japanese approach to management and motivation, theory $\mathrm{Z}$ managers provide rewards, such as long-term employment, promotion from within, participatory management, and other techniques to motivate employees (Ouchi, 1981). It is a management and motivation strategy in planning process basing on long-term employment rewards, promotions from within and participatory management that enhances employee's zeal for increase in production hence organizational performance (Figure 1).

\subsection{Armstrong (2008) Human Resource Planning Theory}

Armstrong (2008) spells out the process of human resource planning that it is not necessarily a linear one, starting with the business strategy and following logically through to resourcing, flexibility and retention plans. 


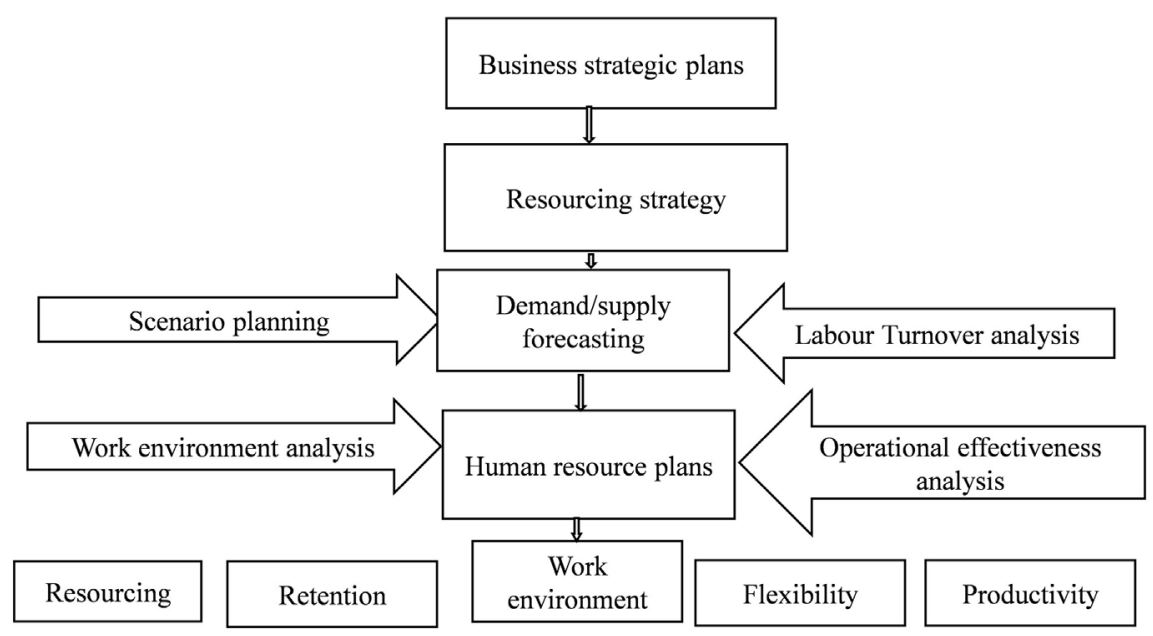

Figure 1. The Process of human resource planning. Source: The Process of human resource Planning suggested by Armstrong (2008).

\subsection{Hendry (1995) Human Resource Planning Theory}

According to (Hendry, 1995) the process of human resource planning may be circular rather than linear, with the process starting anywhere in the cycle. For instance, scenario planning may impact on the resourcing strategy, which in turn, may influence the business strategy. Alternatively, the starting point could be demand and supply forecasts which form the basis for the resourcing strategy. The analysis of labour turnover may feed into the supply forecast, but it could also lead directly to the development of retention plans.

\section{Conceptual Issues in Human Resource Planning and Management}

\subsection{Resourcing Strategy}

According to Keep (1989) the objective of human resource management resourcing strategy is to obtain the right basic material in the form of a work force endowed with the appropriate qualities, skills, knowledge and potential for future training. The selection and recruitment of workers best suited to meeting the needs of the organization ought to form a core activity upon which most other human resource management policies geared towards development and motivation could be built.

\subsection{Components of Resourcing Strategy}

Armstrong (2008) identified three components of resourcing strategy: 1) Resourcing plans: these plans find people from within the organization and/ or for training programs to help learn new skills. If needs are not satisfied from within the organization, resourcing plans prepare longer term by attracting more qualitative candidates as the employer of choice; 2) Flexibility plans: these plans increase the flexibility in the use of human resource to enable the organization to make the best use of people and adapt swiftly to changing circumstance; and 3) 
Relation plan: These plans are intended to retain the people the organization needs. Resourcing strategy provides the basis for the plans within the frame work of business needs. It will be more effective, if it is supported by scenario planning.

\subsection{Scenario Planning}

Scenario planning is also called by the name, the formal strategic planning technique. An advanced learner's oxford dictionary defines a scenario as "an imagined sequence of future events". It is a more or less formalized process for establishing a view about any changes that can be seen to the scale and type of activities in the organization and to its structure. It identifies all external environmental changes that are likely to affect it. It aims at obtaining a better understanding of the possible situation that may have to be dealt with in the future. In this context, (Reilly, 1999) observed that "scenario planning tries to open minds to a range of possibilities that organizations may have to confront". These possibilities are then ordered to produce a series of internally consistent pictures of alternative futures. Scenario planning involves making broad assessment of likely internal developments. It shows the direction in which the organization is going and the implications this has on people requirements.

\subsection{Demand Forecasting}

Demand forecasting is a process of human resource planning by which the number of people, their skills and competencies required for an organization is estimated. The ideal basis of the forecast is an annual budget and longer term business plan, translated into activity levels for each function and department or decision on downsizing.

\subsection{Supply Forecasting}

Supply forecasting is a process of human resource planning by which the number of people to be available within and outside the organization is measured. Supply forecasting is based on the following six factors. An analysis of existing human resource in terms of numbers in each occupation skills and potentials such as, forecasting losses to existing resources through attrition, forecasting changes to existing resources through internal promotion, effecting changing conditions of work and absenteeism Sourcing of supply from within the organization Sources of supply from outside the organization in the national and local labour market.

\subsection{Analysis of Demand and Supply}

The analysis of demand and supply forecast determine whether there are any deficits or surplus. It provides the basis for recruitment, retention and calculations can be made on the number of people lost who may have to be replaced. The analysis of the number of leavers and the reasons why they leave provides 
information that will indicate if any action is required to be taken to improve retention rates. It can encourage further investigations causes and identifying remedies.

\subsection{Labour Turnover}

The analysis of the number of people leaving the organization which include labour turnover or wastage provides data for use in supply forecasting so that calculations can be made on the number of people lost who may have to be replaced. The analysis of the number of leavers and the reasons why they leave encourage further investigations underlying causes and identifying remedies.

\subsection{Internal and External Scanning}

According to Keep (1989) internal scan mainly looks at identifying the factors that an effect on the organization's workforce capabilities necessary to meet the departmental goals. Barrett \& Richard (2006) mentioned that internal analysis gives attention to workforce trends including the age distribution, and portion of positions filled by internal candidates. Each department is responsible for identifying the internal opportunities and challenges. It is necessary for the organization to make and retain strengths to face and reduce the risk and challenges to attain success. Barnard (2006) advised that external analysis should not be a time consuming process. All the potential changes that may occur and their influences may be reviewed by the planning team. Also, team should look at the how the changes impact the organization, its work and recruitment and selection patterns, process of training, retaining and developing the required workforce.

\section{Methodology}

\subsection{Research Design}

This study takes a descriptive research design basing on the quantitative and qualitative data.

\subsection{Data Sources}

Data was obtained from both primary and secondary sources. Primary data was collected using self-administered questionnaires. Secondary data was from review of existing literature.

\subsection{Target Respondents}

The researcher targeted Senior Doctors, Nurses, Accountants, HR personnel and Casual worker of International Hospital Kampala.

\subsection{Population of the Target Respondents within the Case}

From the records obtained from ihk.img.co.ug there were a total of 50 IHK members of staff that constituted of Senior Doctors, Nurses, Accountants, HR personnel, Casual workers. 


\subsection{Sample Size Determination within the Case (Table 1)}

The Sloven's formula was used to determine sample size of target respondent within the case study as follows:

$$
n=\frac{N}{1+N(e)^{2}}
$$

where, $n=$ sample size; $N=$ population size $=50 ; e=$ level of significance 0.05 .

$$
n=\frac{N}{1+N(e)^{2}}=\frac{50}{1+50(0.05)^{2}}=44 \text { respodents }
$$

\subsection{Sampling Technique}

Following the sampling technique employed by Mugenda \& Mugenda (2003), this study employs multistage sampling strategy at two levels: first, the target population is divided into different groups according to their areas of specialization, and second from each stratum, the study employs purposive sampling and simple random sampling to select representative respondents.

\subsection{Data Processing}

After gathering the data from the primary and secondary sources, the data was sorted, edited, coded and entered in Microsoft Excel spread sheet. Inductive reasoning was used to reflect on the topic and a clear understanding about the purpose and objectives of the study before actual data analysis was implemented.

\subsection{Data Analysis}

Data was analyzed using Microsoft Excel. Descriptive statistics by use of simple tabulations were used to present analyzed data.

\subsection{Ethical Considerations}

The study maintained confidentiality of the respondents and protected their privacy at all times.

Table 1. Categorization of respondents within the sample.

\begin{tabular}{ccccc}
\hline No. & $\begin{array}{c}\text { Category of } \\
\text { respondents }\end{array}$ & $\begin{array}{c}\text { Accessible } \\
\text { population }\end{array}$ & $\begin{array}{c}\text { Number of } \\
\text { respondents }\end{array}$ & Methods of sampling \\
\hline 1. & Senior Doctors & 5 & 4 & Purposive sampling \\
2. & Nurses & 5 & 4 & Purposive sampling \\
3. & Accountants & 4 & 3 & Purposive sampling \\
4. & HR personnel & 7 & 6 & Purposive sampling \\
5. & Casual workers & 29 & 27 & Simple random sampling \\
& Total & 50 & 44 & \\
\hline
\end{tabular}

Source: Compiled by the authors. 
The researcher ensured that citations and references of different authors are acknowledged. The researcher tried to be considerate during the interactions with respondents. Informed consent was sought about from the respondents before any interview. The researcher used the language, which is neutral regarding the terminologies involving people and avoid discriminative talk.

\section{Presentation of Findings}

This section presents the empirical findings on the data collected using questionnaires. The purpose of this research is to assess the process of human resource planning on the performance of Health sector using a case study of International Hospital Kampala (IHK). Different statistical techniques were applied to provide answers to the research question by investigating, interpreting and bringing out implications drawn from the findings.

\subsection{Response Rate}

The study targeted 44 respondents and managed to obtain responses from all the respondents thus representing a $100 \%$ response rate. This collaborates with $\mathrm{Mu}-$ genda and Mugenda (2003) recommendations of a response rate of $50 \%$ based on the rule of thumb. Therefore, this study considered the response rate adequate for analysis and generation since it exceeded the minimum recommendation.

\subsection{Reliability of the Items in the Questionnaire}

In line with Burns and Grove (2009), the study employed a Likert scale type questionnaire with a total of eleven (11) questions. Out of the 11 questions, there were seven (7) questions which consisted of multiple Likert questions measured on a scale of $1-4$, of which the scales indicated a respondent's opinion on his/her level of agreement with which a given component of human resource planning influences performance at IHK. In order to understand whether the questions in the questionnaire all reliably measured the same latent variable (i.e. feeling that a given human resource component is essential for performance at IHK), the study estimated the Cronbach's Alfa was run on a sample size of 44 respondents. The estimated Cronbach's Alfa was then used to determine if items in the questionnaire were reliability (internal reliability). Cronbach's alpha ranges from $r=0$ to 1 , with $r=0.7$ or greater considered as sufficiently reliable (Nunnally \& Bernstein, 1994).

The reliability statistics Table 2 for Cronbach's Alfa indicate that the estimated value of Cronbach's alpha is 0.782 , which is above the minimum of 0.70 to indicate a high level of internal consistency. We therefore conclude that the items we included in the questionnaire and the scales used were reliable.

\subsection{Demographic Characteristics of the Respondents}

According to Table 3, it was discovered that the organization employs 53\% 
Table 2. Reliability statistics table for Cronbach's Alfa produced by SPSS, V25.

\begin{tabular}{ccc}
\hline Cronbach's Alfa & Cronbach's Alfa based on standardized Items & No. of Items \\
\hline 0.782 & 0.779 & 7 \\
\hline
\end{tabular}

Source: Compiled by the authors based on returned questionnaires.

Table 3. Responses on gender.

\begin{tabular}{ccc}
\hline Gender & Frequency & Percentage (\%) \\
\hline Male & 23 & 53 \\
Female & 21 & 47 \\
Total & 44 & 100 \\
\hline
\end{tabular}

Source: Primary Data.

males and $47 \%$ females. This implies that the organization employs more male staffs than females, this is because the organization offers medical services, which requires working night shifts and this favors men since most women were married and they have to spend more time at home caring for the family.

According to the results in Table 4, revealed that $68 \%$ of the respondents were in the category of 20 to 30 year, $21 \%$ were between 30 to 40 years, $9 \%$ were aged between 40 to 50 years and $2 \%$ of the respondents were aged 50 years above. The results indicate that the organization employs majority workforce between 20 to 30 years, however this shows that the organization employs young and energetic people. The assumption behind this is that the organizational is private owned and it does not want to employee people who are about to retire it instead prefer employing young people who can at least work with the organization for some good period of time. The other important observation is that IHK uses sophisticated equipment's which need fresh mind equipped with high level of technology.

The results in Table 5 shows that majority of the respondents have worked with the organization for a period ranging between 6 to 10 years (39\%), followed by the respondents who have worked for a period ranging between 1 to 5 years (36\%), followed by the respondents who have worked for a period below 1 year (25\%), then the organization does not have respondents who have worked above 10 years. This implies that the organization awards long term contracts to employees. The assumption of this is that, IHK considers experience of employees as one of the most important factor and also the other observation is that the organization offers good remuneration packages to its employees. That is why most of them have worked with the organization for quite long time.

According to the information in Table 6, majority of the respondents hold a bachelor's degree which takes $31 \%, 16 \%$ of the respondents holds a master's degree, $11 \%$ of the respondents holds a doctorate, $11 \%$ of the organization's employees holds a diploma, $11 \%$ of the respondents holds an ordinary certificate of education, $10 \%$ of the respondents holds an advanced certificate of education, 
Table 4. Responses on age.

\begin{tabular}{ccc}
\hline Age & Frequency & Percentage (\%) \\
\hline $20-30$ & 30 & 68 \\
$30-40$ & 9 & 21 \\
$40-50$ & 4 & 9 \\
50 above & 1 & 2 \\
Total & 44 & 100 \\
\hline
\end{tabular}

Source: Primary data.

Table 5. Responses on the duration at work.

\begin{tabular}{ccc}
\hline Duration & Frequency & Percentage (\%) \\
\hline Below 1 year & 11 & 25 \\
1 to 5 year & 16 & 36 \\
6 to 10 years & 17 & 39 \\
Above 10 years & 0 & 0 \\
Total & 44 & 100 \\
\hline
\end{tabular}

Source: Primary data.

Table 6. Responses on the level of qualifications.

\begin{tabular}{ccc}
\hline Education level & Frequency & Percentage (\%) \\
\hline Ordinary level & 5 & 11 \\
Advanced level & 4 & 10 \\
Certificate level & 4 & 10 \\
Diploma level & 5 & 11 \\
Bachelor's level & 14 & 31 \\
Master's degree & 7 & 16 \\
Doctorate & 5 & 11 \\
Others & 0 & 0 \\
Total & 44 & 100 \\
\hline
\end{tabular}

Source: Primary Data.

$10 \%$ of the respondents also hold a certificate from different discipline of education and there was no respondents with other different level of qualification. This implies that the organization employs more workers of bachelor's and master's degree level, the assumption of this is that, IHK prefers employing highly skilled workers given the nature of business it deals in. IHK seem not to compromise with the level education when it comes to sourcing of employees, it always want to deliver quality services through using highly educated personnel.

\subsection{Findings on the Process of Human Resource Planning and the Performance of Health Sector in Uganda}

This section shows opinions of different respondents from International Hospit- 
al Kampala about this research. The opinions were coded using figures in order for the researcher to consistently observe both quantitative and qualitative element of this research. In the tables below; 1) stands for agree, 2) stands for strongly agree, 3) stands for disagree 4) stands for strongly disagree.

We compile a frequency distribution table on the processes of human resource planning at IHK and also employ a t-test on the difference between two sample means in order to ascertain whether there was a difference in the means of the number of respondents who agreed and those who strongly agreed on the various components of human resource planning process as shown in Table 2. We do this in order to determine the most significant human resource planning process components that are mostly embraced at IHK. The results from the t-test do not reject the null hypothesis that there is no difference in the means of the number of respondents who agreed and those who strongly agreed on the various components of human resource planning process at IHK.

\section{Discussion of the Results}

Results from Table 7 show that $36 \%$ of the respondents strongly agreed, $30 \%$ agreed, $14 \%$ disagreed and $20 \%$ of strongly disagreed that determination of goals is part of the process for human resource planning that helps enhance organizational performance. The results thus show that a total of $66 \%$ either agreed or strongly agreed that determination of goals is part of the process for human resource planning at IHK.

Table 7. Findings on the process of human resource planning and the performance of Health sector in Uganda.

\begin{tabular}{|c|c|c|c|c|c|c|c|c|}
\hline \multirow{2}{*}{$\begin{array}{c}\text { Human Resource } \\
\text { Planning Components }\end{array}$} & \multicolumn{2}{|c|}{1} & \multicolumn{2}{|c|}{2} & \multicolumn{2}{|c|}{3} & \multicolumn{2}{|c|}{4} \\
\hline & Freq. & $\%$ & Freq. & $\%$ & Freq. & $\%$ & Freq. & $\%$ \\
\hline Determination of goals & 13 & 30 & 16 & 36 & 6 & 14 & 9 & 20 \\
\hline Environmental scanning & 10 & 24 & 17 & 38 & 9 & 21 & 8 & 17 \\
\hline Internal scanning & 14 & 32 & 14 & 32 & 9 & 20 & 8 & 17 \\
\hline External scanning & 13 & 31 & 16 & 36 & 8 & 18 & 7 & 15 \\
\hline Performing gap analysis & 15 & 34 & 13 & 30 & 9 & 20 & 7 & 16 \\
\hline Decide human resource priorities & 14 & 32 & 13 & 31 & 5 & 11 & 12 & 26 \\
\hline $\begin{array}{l}\text { Measuring, monitoring } \\
\text { and reporting the progress }\end{array}$ & 12 & 27 & 15 & 34 & 9 & 20 & 8 & 18 \\
\hline \multicolumn{9}{|c|}{ Paired t-test on the difference between the mean number of } \\
\hline $\begin{array}{l}\mathrm{H}_{\mathrm{o}}: \mathrm{m} \\
\mathrm{H}_{\mathrm{a}}: \mathrm{m}\end{array}$ & $\begin{array}{l}\text { n (agre } \\
\text { n (agre } \\
\operatorname{Pr}(|\mathrm{T}|\end{array}$ & $\begin{array}{l}-s t r \\
-s t r \\
|t|)\end{array}$ & $\begin{array}{l}\text { igly agr } \\
\text { igly age } \\
.1616\end{array}$ & $\begin{array}{l}e)=0 \\
e) \neq 0\end{array}$ & & & & \\
\hline
\end{tabular}

Source: Primary Data. 
The results also show that $38 \%$ of the respondents strongly agreed, $24 \%$ of the respondents agreed, $21 \%$ disagreed and 17\% strongly disagreed that environmental scanning is part of the process of human resource planning. The results thus show that a total of $62 \%$ either agreed or strongly agreed that environmental scanning is part of the process for human resource planning at IHK.

The results also show that $32 \%$ of the respondents agreed, $32 \%$ of the respondents strongly agreed, $20 \%$ disagreed and $16 \%$ of the respondents strongly disagreed that internal scanning as part of the process of human resource planning used by IHK. The results thus show that a total of $64 \%$ either agreed or strongly agreed that internal scanning is part of the process for human resource planning at IHK.

The study findings further indicated that $36 \%$ of the respondents strongly agree, $31 \%$ of the respondents agreed, $18 \%$ of the respondents disagreed and $7 \%$ strongly disagreed agreed that external scanning is exercised by IHK as part of the process of human resource planning. The results thus show that a total of $67 \%$ either agreed or strongly agreed that external scanning is part of the process for human resource planning at IHK.

The results also revealed that $34 \%$ of the respondents agreed, $30 \%$ of the respondents strongly agreed, $20 \%$ disagreed and $16 \%$ of the population strongly disagreed that performing gap analysis is part of the process of human resource planning for organizational performance. The results thus show that a total of $64 \%$ either agreed or strongly agreed that perfuming gap analysis is part of the process for human resource planning at IHK.

The findings also showed that $32 \%$ of the respondents agreed, $31 \%$ of the respondents strongly agree, $11 \%$ disagreed and $26 \%$ of the respondents strongly disagreed that deciding human resource priorities is part of the process of human resource planning for organizational performance of IHK. The results thus show that a total of $63 \%$ either agreed or strongly agreed that deciding human resource priorities is part of the process for human resource planning at IHK.

In the study, the results showed that $34 \%$ of the respondents strongly agree, $27 \%$ of the study population agreed, $20 \%$ disagree and $18 \%$ of the study population strongly disagree that measuring, monitoring and reporting the progress is part of the process followed at IHK. The results thus show that a total of $61 \%$ either agreed or strongly agreed that measuring and monitoring the progress is part of the process for human resource planning at IHK. The assumption is that the organization follows human resource planning process to carryout human resource activities such as segregation of duties and this confirms the fact that human resource planning plays a significant role on the organizational performance.

The results of the study agree with (John, 2008) his views that "this conventional wisdom represents human resource planning as an embracing policy making activity producing on a rolling basis, precise forecasts using technically sophisticated and highly integrated planning system" He suggests that it is better 
regarded as, first, monitoring activity, through which human resource stocks and flows and their relationship to business needs can be better understood, assessed and controlled, problems highlighted and a base established from which to respond to unforeseen events, and second, an investigatory activity by which the human resource implications of particular problem and changing situations can be explored and the effects of alternative policies and actions investigated. The findings also agree with (Armstrong, 2008) who spells out the process of human resource planning that it is not necessarily a linear one, starting with the business strategy and following logically through resourcing, flexibility and retention plans. And also the findings seems to agree with (Hendry, 1995) who explained the process of human resource planning that it might be circular rather than linear, with the process starting anywhere in the cycle. For instance, scenario planning may impact on the resourcing strategy, which in turn, may influence the business strategy. Alternatively, the starting point could be demand and supply forecasts which form the basis for the resourcing strategy. The analysis of labour turnover may feed into the supply forecast, but it could also lead directly to the development of retention plans.

\section{Conclusion}

In consideration of the respondents who were in agreement (either agreed or strongly agreed) with the various components of human resource planning processes, the study results show that external scanning (67\%) and determination of goals $(66 \%)$ are the most important human resource planning processes embraced at IHK. The results nevertheless show that the other components of human resource planning process such as Internal scanning (64\%), performance gap analysis (64\%), decide human resource priorities (63\%), Environmental scanning (62\%) and Measuring, monitoring and reporting the progress (61\%) are nearly equally important components of human resource planning process that influence performance at IHK.

\section{Recommendations}

On the basis of the findings from this study, we offer the following recommendations;

1) The human resource planning departments of IHK should focus on scanning the external community and determination of goals components of human planning resource process, in this they should concentrate mainly on the strength and weaknesses of competitors and knowing the strategies they use to maintain their human resources which will help the organization to plan for the betterment of its staff and enhance its performance.

2) The departments at IHK should further establish a transparent recruitment and selection programs that enhance the public image of the organization and proper utilization of Human Resources.

3) The Ministry of Health should work towards matching human resource 
planning process with organizational strategic goals, to achieve this, the ministry should clearly define its vision and mission to the staff and partner organizations in a concise manner, which will help them focus and deliver good results and thus enhance performance of the entire sector in Uganda.

4) IHK should embrace the use of modern technology in the recruitment and selection of staff like use of various soft wares such as Won score and Spur, this is so as a result of internal scanning and thus, will result into hiring of more competitive and diverse employees.

\section{Recommendations for Further Research}

The study has dealt with the investigation of human resource planning process and its influence on the performance of health sector in Uganda, a case study of IHK. It is recommended that a study be conducted on the assessment of the role of government in human resource planning process and its influence on the performance of the health sector and also further research on the relevancy of electronic human resource planning on the organizational performance.

\section{Conflicts of Interest}

The authors declare no conflicts of interest regarding the publication of this paper.

\section{References}

Armstrong, M. (2008). Human Resource Management and Practice.

Barnard, W. (2006). Seven Steps of Effective Workforce Planning.

Barrett, K., \& Richard, G. (2006). Seven Steps of Effective Workforce Planning, When Boomers Retire. Governing Magazine.

Hendry (1995). Human Resource Management: A Strategy Approach to Employment Butterworth Hemimann-Oxford.

Keep, E. (1989). Corporate Training Strategies in J Story, New perspectives on HRM, Blackwell, Oxford.

Minister of Health (2008a). Annual Health Sector Performance Report 2007/08. Kampala: Ministry of Health.

Ministry of Health (2008b). Annual Health Sector Strategic Plan 2005/06-2009/10: Mid-Term Review. Kampala: Ministry of Health.

Mugenda, O. M., \& Mugenda, A. G. (2003). Research Methods: Qualitative and Quantitative Approaches. Nairobi: Acts Press.

Ouchi, W. G. (1981). Theory Z: How American Business Can Meet the Japanese Challenge. Reading, MA: Addison-Wesley. https://doi.org/10.1016/0007-6813(81)90031-8

Rao (2010). Management of Organizational Behavior (1st Edition). Mumbia: Himalaya Pub. House.

Reilly, P (1999). The Human Resource Planning Audit. Cambridge: Cambridge Strategy Publications. 